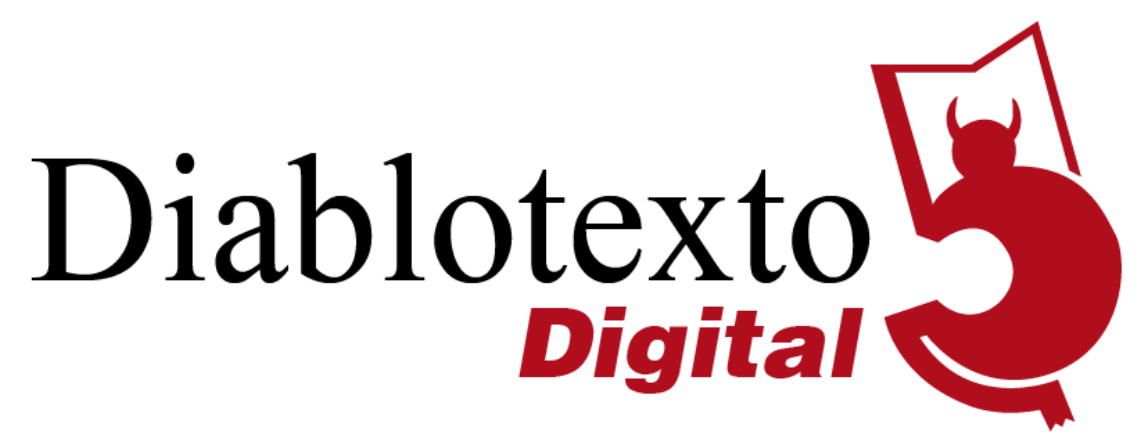

Cultura Libre o Derechos de autor ¿una disyuntiva innecesaria en el siglo XXI?

Free Culture or Authors' rights. An unnecessary dilema in the 21 st century?

\author{
ROSA-ANNA FERRANDO-MATEU \\ UNIVERSITAT JAUME I DE CASTELLÓ
}

Resumen: El presente estudio versará alrededor de los conceptos de derechos de autor y de cultura libre, de la importancia de la propiedad intelectual y su mercantilización. De esta forma, observaremos cómo estos derechos de autor han pasado a formar parte de un entramado de leyes, perdiendo el propio autor su derecho a la obra y pasando éste a un tercero. Con la ayuda de la idea que nos propone Lawrence Lessig en su libro Cultura libre. Cómo los grandes medios están usando la tecnología y las leyes para encerrar la cultura y controlar la creatividad, expondremos cómo existe una tensión entre los intereses que hay detrás de la propiedad intelectual.

Palabras clave: Cultura Libre, Derechos de autor, Dominio público

Abstract: The present study will deal with the concepts of Authors' rights and Free Culture, the importance of intellectual property and its commercialization. In this way, we will observe how these authors' rights have become part of a tangle of laws, having lost the author himself his right to the work and passing this on to a third party. With the help of the idea proposed by Lawrence Lessig in his book Free Culture: How Big Media Uses Technology and Law to Lock Down Culture and Control Creativity, we will expose ho there is a tension between the interests behind intellectual property.

Key words: Creative Commons, Copyright, Free Culture, Authors' rights, Public domain 


\section{Propiedad Intelectual}

Definir el concepto de 'propiedad intelectual' es complejo, ya que unir la propiedad con lo intelectual no es cuestión sencilla. La característica principal de la propiedad es la exclusión, es decir, el derecho del propietario frente a cualquiera a excluirlo del uso y goce de lo que posee. En cambio, lo intelectual es aquello que no tiene forma física, que es etéreo, intangible, y que moralmente debe ser compartido puesto que contribuye, de una forma $u$ otra, a mejorar el mundo y la civilización, y hacer la vida más sencilla o, simplemente, más agradable al conjunto de la humanidad. Como dice Luis Felipe Ragel, "la propiedad intelectual no es realmente una propiedad porque su objeto no es una cosa externa, sino que surge de la mente y de las cualidades personales del creador" (2005: 19).

Cuando hablamos de 'propiedad intelectual' nos referimos a un tipo de bienes que no son corpóreos. Algunos ejemplos ilustrativos pueden ser las ideas, la denominación de origen, los intérpretes, entre otros... Al denominarla como propiedad tendemos a relacionarla con un bien material y tangible, y en palabras de Lawrence Lessig en su libro Cultura libre. Cómo los grandes medios están usando la tecnología y las leyes para encerrar la cultura y controlar la creatividad $^{1}$,

\footnotetext{
mientras que la 'propiedad creativa' es ciertamente 'propiedad' en el sentido escolástico y preciso en el que se educa a los abogados para entender estas cuestiones, nunca se ha dado el caso, y nunca debería darse, de que 'los dueños de la propiedad creativa' hayan 'recibido los mismos derechos y protecciones que los demás dueños de una propiedad (2004: 138).
}

La propiedad intelectual es un objeto que puede reproducirse y explotarse a través de copias, cuyas facultades patrimoniales tienen carácter temporal y la mayoría de facultades son de carácter moral (Ragel, 2005: 19). La propiedad creativa y la propiedad, propiamente dicha, son tratadas de diferente manera, ya que la primera a partir de un tiempo se ha de incorporar al dominio público, sin

\footnotetext{
${ }^{1}$ Elegimos este libro como punto de partida en nuestro trabajo porque aun siendo publicado en el año 2004, fue Lawrence Lessig quien propuso el concepto de cultura libre, conformada por cuatro corrientes de pensamiento: el dominio público, el Copyleft, las licencias Creative Commons y el software libre que posteriormente lo plasmó en dicho libro.
} 
la obligación por parte del gobierno de abonar una compensación por su expropiación. Es decir, el hecho mismo de la intangibilidad de lo creativo es una característica elemental de estos 'bienes', dado que esta cuestión afecta de forma directa a su protección en cuanto a elementos sujetos a una propiedad.

En la actualidad, vivimos en una sociedad aparentemente libre, decimos aparentemente porque en un mundo globalizado donde los medios de comunicación juegan un papel socializador y educativo, la ciudadanía vive inmersa en una espiral de campañas publicitarias que incentivan el consumo de determinados productos y condiciona, por tanto, nuestra libertad individual en la medida en que estamos siendo constreñidos a una campaña constante de convencimiento para elegir un producto y no otro. Es por eso que resulta difícil que podamos decir abiertamente que somos libres. En esta sociedad, junto a un mercado liberalizado y global, el gobierno debe dejar actuar en libertad sin frenar los avances, ya que de modo contrario implicaría negar el progreso. Y una sociedad que "defiende los ideales de la cultura libre debe preservar precisamente la oportunidad de que la nueva creatividad amenace a la vieja" (Lessig, 2004: 139).

En el contexto de las leyes que regulan la libertad de expresión, hay que caminar con cautela frente a las exigencias de la industria que quiere imponer cargas a la libertad de expresión y a la creatividad. Puesto que es posible que esta sobreprotección antinatural, en un momento en el que los contenidos se multiplican cada minuto y están al alcance de cualquiera, puede ser un impedimento para que esas ideas positivas, a las que nos hemos referido anteriormente, lleguen al máximo público posible.

\section{Derechos de autor y copyright}

Es importante que tengamos presente la diferencia entre derechos de autor y copyright, ya que estos dos conceptos tienen orígenes relativamente distintos. Antes de centrarnos en el debate actual, es conveniente exponer un breve acercamiento histórico. 
En tiempos en que los copistas medievales transcribían a mano los libros, no tenía ningún sentido poner límites a la acción de copiar. Existía el derecho de copia que incluía la capacidad de transformación. Los manuscritos originales iban transformándose lentamente en cada copia nueva, ya que era un proceso manual.

Sin embargo, en la Edad Media comienzan a aparecer elementos que inician el camino de la reivindicación de la autoría y la figura del autor como propietario de la obra. Encontramos dos autores en el siglo XIV que opinan sobre la autoría de su obra. Por un lado Don Juan Manual, en el prólogo del editor de la obra Conde Lucanor podemos observar cómo nos indica que,

\begin{abstract}
Este libro fue escrito por don Juan, hijo del muy noble infante don Manuel, [...]. Como don Juan ha visto y comprobado que en los libros hay muchos errores de copia, pues las letras son muy parecidas entre sí y los copistas, al confundirlas, cambian el sentido de muchos pasajes, por lo que luego los lectores le echan la culpa al autor de la obra, pide don Juan a quienes leyeren cualquier copia de un libro suyo que, si encuentran alguna palabra mal empleada, no le culpen a él, hasta que consulten el original que salió de sus manos y que estará corregido, en muchas ocasiones, de su puño y letra².
\end{abstract}

En cambio, en una postura totalmente opuesta, encontramos a Juan Ruiz, arcipreste de Hita. En "De cómo dice el arcipreste que se ha de entender su libro" del Libro del buen amor da permiso y explicaciones del uso de su obra para ser cambiada y transformada.

\footnotetext{
Qualquier omen, que lo oya, si bien trovar sopiere,

Puede más y añadir et emendar si quisiere,

Ande de mano en mano a quienquier quel' pidiere,

Como pella a las dueñas quien podiere ${ }^{3}$.
}

Con la aparición de la imprenta, en el siglo XV, esa transformación producida por la copia manual dejaba de darse, y de este modo el texto quedaba fijado. También el número de textos reproducidos y su difusión aumentan y, según Igor Sádaba, aparece "la cuestión de la difusión de la información y la cultura entre nuevas capas de la sociedad" (2008: 29). Pero hacer copias

2 http://www.cervantesvirtual.com/obra-visor/el-conde-lucanor--0/html/ [Fecha de consulta: 10 de septiembre de 2017].

${ }^{3} \mathrm{http}: / /$ www.cervantesvirtual.com/obra-visor/el-libro-de-buen-amor--0/html/ [Fecha de consulta: 10 de septiembre de 2017]. 
implicaba un esfuerzo industrial, ya que el editor invertía en una maquinaria, y es por eso que solicitaran a la corona un sistema de protección que consistía en conceder al editor derecho sobre sus copias durante un periodo de exclusividad (Busaniche, 2012: 5). De aquí que el copyright es derecho de copia y nada tiene que ver con los derechos de autor.

En el siglo XVI, en Occidente, para regular el uso descontrolado de imprentas, se estableció en Francia una primerísima ley cuya aplicación fue irrealizable, pasando desapercibida (Sádaba, 2008: 29). Será en 1710 cuando aparece en Inglaterra la primera normativa de copyright que se encuentra en el Estatuto de la Reina Ana promulgada el 10 de abril de ese mismo año. Con este estatuto se pretendía corregir los problemas sobre los derechos de la explotación de libros y eliminar los monopolios de los editores. Se establecía un monopolio de catorce años tras la publicación, extensible a catorce años más si el autor así lo decidía. Pasado ese tiempo, la obra ingresaba al dominio público y, por tanto, cualquier editor podría reproducirla libremente. En un principio, una obra tenía que registrarse antes de recibir la protección del copyright pero, más tarde, esto cambió y la obra lo adquiría ex lege sin necesidad de registrarla. "La ley introducía dos conceptos nuevos: la figura del autor y el principio de una duración fija, aunque no definida, para la protección" (Sádaba, 2008: 31).

En 1755 se publica la Enciclopedia francesa. En el tomo V aparece la entrada "Derecho de copia" donde se establece claramente que la prioridad es el derecho de propiedad del autor sobre su obra. Durante el siglo XVIII, en un momento de expansión jurídica, aparecen por el resto de países europeos las diferentes legislaciones nacionales con clara influencia de la llustración, más que con el modelo inglés. (Sádaba, 2008: 32-33).

Estados Unidos copió las leyes inglesas de copyright y las mejoró. En su Constitución se dicta que el Congreso tiene la facultad de fijar monopolios temporales sobre creaciones e inventos con el fin explícito de fomentar las artes y las ciencias. Y es en 1790, en su primer Congreso, donde se promulgarán las primeras leyes para proteger la propiedad creativa. Aunque los norteamericanos "recelaban de los monopolios [...], accedieron a esta forma limitada de 
monopolio a cambio de garantizar el fomento de la innovación" (Sádaba, 2008: 36).

Esta primera ley ha experimentado modificaciones hasta la actualidad. Se ha ampliado los años de control y retrasado el acceso al dominio público, hasta el punto de que cada día es más difícil que una obra llegue al dominio público. Todo esto hace necesario que debamos plantearnos sí, a día de hoy, podemos seguir tratando el copyright como hace doscientos años, pues en vez de liberarlo, lo hemos restringido.

Si volvemos a este recorrido histórico, es conveniente recordar que los derechos de autor surgen esencialmente con el pensamiento francés de finales del siglo XVIII. El derecho de autor se basa en la idea de un derecho personal del autor, fundado entre la relación del autor con su creación y comprende "el conjunto de facultades inherentes a la persona del autor por el hecho de haber una obra artística, literaria o científica” (Pérez de Ontiveros, 1993: 34).

Según afirma Beatriz Busaniche, "el derecho de autor cubre las 'expresiones de ideas' bajo la forma de obras. Esto significa que las ideas no quedan cubiertas como tales, sino su expresión en un texto, un dibujo, un diseño, una fotografía, etc." (2012: 16). En cambio, el copyright se limita estrictamente a proteger la difusión y copia de la obra, sin considerar los atributos morales del autor en relación a la misma, excepto su paternidad; por lo que sólo asigna derechos sobre la utilización, copia y difusión de una obra

\section{Dos modelos enfrentados}

Encontramos dos modelos muy diferenciados a la hora de tratar el copyright y los derechos de autor: por un lado, el modelo europeo y, por el otro, el estadounidense. El derecho de copyright europeo, más concretamente el modelo francés, se basa en el derecho moral otorgado a los autores para que estos mantengan el control sobre lo que crean. En cambio, Estados Unidos se resistió a "importar la doctrina del derecho moral al derecho de copyright" (Goldstein, 1999: 152). Paul Goldstein, nuevamente, nos señala la diferencia entre los dos modelos que existen, 
La doctrina del derecho moral de autor y su rechazo en los Estados Unidos como prueba de una división profunda que separa las dos culturas del copyright -la cultura europea, compartida con otros países- [...] La cultura europea del copyright coloca a los autores en el centro, otorgándoles por una cuestión de derecho natural, el control de todos los usos de sus obras que puedan afectar a sus intereses. De hecho, muchos países europeos llaman a sus leyes que protegen las obras literarias y artísticas, no leyes de 'copyright', sino leyes sobre 'derechos de autor' [...]. Por el contrario, la cultura americana del copyright se centra en el cálculo estricto y utilitario que equilibra las necesidades de los productores de copyright con las de los consumidores (1999: 153).

Los Estados Unidos, paradójicamente, tienen una visión más social y colectiva de los derechos de autor y, como ya hemos dicho, se han negado a aceptar algún tipo de derecho moral para los autores, mientras que en Europa se han centrado más en los creadores. Según las leyes europeas, existen unos derechos individuales que deben proteger a los autores de las creaciones. En cambio, en Estados Unidos "no se plantea la existencia o no de autor o de obra, sino si se necesita la protección para asegurar la producción y difusión social del producto" (Sádaba, 2008: 138-139), anteponen la producción a los derechos del autor.

Esta división entre las dos posturas ante el tratamiento del copyright comporta consecuencias legales y económicas y más, en la actualidad, ya que vivimos en un mundo globalizado en el que estamos conectados y en contacto con diferentes países y culturas. Aún existiendo diferencias, los dos modelos tienen en común muchos puntos.

\section{Radio de acción}

Podemos observar que, junto a la duración del copyright, también el radio de acción ha aumentado. Según Lessig este componente "es la gama de derechos concedidos por las leyes" (2004: 157). En 1790, ese ámbito era muy pequeño, donde el derecho concedido por un copyright le otorgaba al autor el derecho a publicar las obras con copyright. Ese derecho era exclusivo a obras determinadas y no se extendía a las obras derivadas. Pero en la actualidad, esto ha cambiado y los derechos cubren también a la obra derivada que es reducida a una forma tangible (la música, la arquitectura, el teatro y los programas informáticos). 
De este modo, el dueño del copyright de una obra creativa tiene el derecho sobre su obra y también el control sobre cualquier tipo de copia de esa obra, "este derecho le da al dueño del copyright control sobre no sólo su obra en particular, sino también sobre cualquier 'obra derivada' que pueda surgir a partir de la obra original" (Lessig, 2004: 158).

En definitiva, la protección que te ofrece el copyright es el control a que otros hagan una copia de tu obra, no importa el porqué, prohibiendo no sólo la copia de la obra sino la obra derivada de ésta, y de este modo no permite la transformación de la obra original en otra. Esta expansión en la protección a la creación es un cambio significativo con respecto a los derechos originalmente concedidos. Y es que, en la era digital, como dice Lessig:

\footnotetext{
La tecnología expande el radio de acción del control verdadero, porque la tecnología crea una copia dentro de cada transacción. [...] Permitir que la tecnología haga efectivo el control del copyright significa que el control del copyright ya no está definido por una política equilibrada. El control del copyright es simplemente lo que escogen los dueños privados (2004: 168-169).
}

No debemos olvidar que en internet las reglas las hacen cumplir las máquinas y no los seres humanos. Son controles al acceso a los contenidos, y estos controles están diseñados por programadores; las leyes de copyright pasan a ser tratadas como códigos de copyright. Es el código y no la ley el que manda. "Las nuevas tecnologías de la información y de la comunicación limitan y enfrentan la ley, colocando a los $\mathrm{DPI}^{4}$ en situación de franca desventaja en relación con las nuevas culturas del ‘copy\&paste' o 'rip, mix \& burn”' (Sádaba, 2008: 39). En nuestra era, mediante la tecnología se pueden controlar los usos de los contenidos, y con esta regulación del proceso creativo regulamos la creatividad individual.

Junto al poder de la tecnología para cooperar al control de la ley, aparece el poder de los mercados que se encuentran concentrados y, de este modo, consiguen reducir las oportunidades y así, evitar que surjan voces discrepantes. Quiere decir que la creación, o al menos aquella a la que tenemos mayor y mejor acceso, está en manos de unos pocos, teniendo el poder de manipular la cultura

\footnotetext{
${ }^{4}$ Derechos de Propiedad Intelectual.
} 
y las creaciones artísticas y, de esta manera, hacer desaparecer tanto la oposición como la competencia. Si hacer cumplir de forma estricta los amplios y expandidos derechos de 'propiedad', concedidos por el copyright, implica limitar la libertad para crear y desarrollar nueva cultura, surge la duda si ese concepto de propiedad debería redefinirse y delimitarse (Lessig, 2004: 192).

\section{Hacia una Cultura Libre}

Cuando Lawrence Lessig proclama una Free Culture en su libro homónimo, con traducción literal al español Cultura libre, Lessig se refiere, sobre todo, a que la cultura sea liberada. Es decir, lo que pretende es hacer un llamamiento por la emancipación de la cultura, al romper todas las ataduras creadas por las leyes.

En las últimas décadas, el poder del copyright y de las nuevas tecnologías de distribución y creación han crecido drásticamente. Esta forma de regulación es ahora una masiva regulación de todo el proceso creativo. La ley ahora regula por completo la creatividad. Y con esta regulación, se coarta, como hemos dicho, el proceso creativo de los autores.

Sin embargo, Joost Smiers nos propone que existe vida más allá del copyright, apostando por encontrar alternativas para "proteger el conocimiento y la creatividad pertenecientes al dominio público y asegurar unos ingresos justos a muchos artistas y empresarios culturales" (2006: 287).

Encontramos otras opciones, como las licencias libres, donde los derechos de autor salvaguardan a los propios autores para disponer sobre su obra. Idea que, por otra parte, nos viene dada por una tradición cultural de la figura del artista/genio romántico. Pero la autocrítica del arte contemporáneo en el siglo xx quiso romper con ella. Es con la irrupción de las nuevas tecnologías, como la fotografía, el cine y las imágenes digitales, cuando estos procesos de autocrítica se afianzan (Pagola, 2012: 31).

En el año 2001, los creadores digitales concibieron un nuevo sistema de licencias que permitían ceder algunos derechos bajo unas determinadas condiciones, conocidas como licencias Creative Commons. Entre los miembros 
fundacionales ${ }^{5}$ encontramos al propio Lessig. Mediante las mismas el autor cede algunos de los permisos sobre su trabajo: el autor cede su obra si hay reconocimiento de ella, si no hay beneficio de un uso comercial o si se comparte la nueva obra con los mismos permisos que la obra ya existente. Constituye una de las iniciativas más difundidas y, de este modo, se asegura una cultura y una creatividad más libres.

Antes de la existencia de este tipo de licencias, el autor se veía obligado a que su obra estuviera atada a un copyright (ya que éste se creaba de forma automática), pero con la aparición de estas nuevas licencias, el autor tiene más poder sobre su propia obra y posee la libertad legal de ofrecerla al público, sin que sufra ninguna sanción. No solo creando textos libres, sino también bancos de imágenes o de música para que éstos sean transformados en una idea nueva. Este tipo de conocimiento abierto y en red tiene cada vez más adeptos, debido a que el hecho de convertir el esfuerzo en algo público conlleva su recompensa en la difusión obtenida.

Según Smiers, "mientras el sistema de copyright tenga vigencia, la licencia de Creative Commons sería una solución posible [...] no obstante hay cuestiones que no quedan del todo claras" (2006: 288), como son, la obtención de beneficios económicos de los artistas y sus patrocinadores, por eso muchos artistas se resisten a acabar con el sistema del copyright hasta que no encuentren una alternativa clara.

El documental danés Copiar es correcto, copiar es malo: Un documental sobre el estado actual del copyright y la cultura (2007), dirigido por Andreas Johnsen, Ralf Christensen y Henrik Moltke, ofrece un breve repaso sobre el tema del copyright en la era de internet. En el nuevo espacio musical donde la remezcla ${ }^{6}$ y el sampler, junto a la facilidad de difusión en un entorno digital,

\footnotetext{
${ }^{5}$ El representante de Creative Commons en España es Ignasi Labastida, responsable de la Unidad de Investigación y de la Oficina de Difusión del Conocimiento de la Universitat de Barcelona.

${ }^{6}$ Remezcla, traducción literal de la palabra inglesa remix. Inicialmente este término es utilizado en la música, que viene a significar la mezcla de una o varias muestras (sample) de una música original, normalmente el estribillo, para dar una versión alternativa. En la actualidad, en el arte contemporáneo, estos procesos transformativos que se apropian de obras ya existentes, lo encontramos en diferentes técnicas de trabajo como son en los collages o en piezas audiovisuales a partir de fragmentos sacados de youtube.
} 
fomentan la creatividad, pero se encuentra amenazada por las legislaciones particulares. Así encontramos el ejemplo de un joven músico, Girl Tank, conocido en la escena de la mezcla, que incorpora sonidos de otras músicas en sus obras (en ocasiones sólo segundos) que si tuviera el dinero para poder conseguir todos los derechos para transformar la música de otro autor, entraría en la maraña de los permisos legales y le sería imposible.

Si no damos libertad a nuestra obra, como dice Lessig, ocurrirá que "la oportunidad de crear y transformar queda debilitada en un mundo en el que la creación requiere pedir permiso y la creatividad tiene que consultar con su abogado" (2004: 197). Porque no tenemos que olvidar que la cultura cambia y evoluciona, se encuentra en constante desarrollo no surge de la nada. Siempre mira al pasado para transformarse, rebelarse, oponerse y, de este modo, crear futuro y evolucionar.

Otra forma alternativa al copyright la hallamos en la mayoría de países no occidentales, como también nos muestra el documental citado, donde "la concepción individualista del copyright occidental no se ajusta bien al carácter colectivo de la creación y la representación" (Smiers, 2006: 289).

En el norte de Brasil encontramos una forma de música que mezcla música tradicional propia y música pop del momento conocida como Tecnobrega, que surge en el verano de 2002 en la ciudad de Belém, capital del estado de Pará. A partir de 2003 comenzó su expansión como "fenómeno cultural popular paralelo, beneficiándose de las nuevas redes sociales y del comercio informal de discos" (Barros, 2016: 166). Mediante la apropiación de "la producción musical de tecnologías de bajo costo, junto con la flexibilidad de los derechos de propiedad intelectual, posibilita la formación de mercados culturales igual o más viables que los modelos habituales" (Barros, 2016: 169).

En la actualidad sigue siendo una novedad como fenómeno cultural. La revolución del Tecnobrega, como modelo de negocios en el siglo XXI, es una innovación que promueve la piratería como medio más económico para popularizar artistas y, a su vez, ganar dinero con actuaciones en directo en los festivales. Según Nelson Motta, "los críticos dicen que el Tecnobrega fomenta la 
tolerancia a la piratería, [...] los defensores del Tecnobrega dicen que esta música ofrece a la industria un camino innovador" (2008) ${ }^{7}$.

En la industria cinematográfica, encontramos el ejemplo de Nigeria que se caracteriza por su prolífica producción de películas de bajo presupuesto, grabadas con cámaras digitales, producidas en formato DVD-video y vendidas directamente a los consumidores. El proceso de producción, desde la elección del reparto hasta la distribución, no llega a los dos meses. Según Madu Chikwendu:

El modelo de Nollywood es muy fácil de entender. Se trata de un sistema de producción basado en el uso de equipos digitales de video. Las películas van directamente al formato DVD para la venta y el alquiler. Es muy dinámico y muy eficiente. El sistema de distribución está también muy poco estructurado. Los DVD se copian por miles y luego se distribuyen [...] en grandes mercados mayoristas de Lagos, Kanu y Onitsha (2007: 9).

Estas acciones nos recuerdan, de algún modo, la necesaria actitud crítica al sistema de consumo internacional, donde la subversión también parte de la complicidad del consumidor.

Dentro del territorio nacional mediante el uso de plataformas de transmisión de video por flujo continuo (como es el caso de la plataforma iROKOtv) y con campañas realizadas por parte del Gobierno de Nigeria para mejorar el conocimiento sobre la Propiedad Intelectual en la industria cinematográfica (Oyewole, 2014: 3) se ha conseguido concienciar a la población nacional del problema de la piratería. Falta ahora encontrar una solución a nivel transnacional.

El proyecto editorial español Traficantes de Sueños ${ }^{8}$ apuesta por la cultura libre, pero no hay que olvidar que "libre no es gratis" y, los proyectos de cultura libre necesitan la implicación de la comunidad. La labor editorial tiene como objetivo facilitar el acceso a la cultura y al conocimiento, y por ello, los textos se

\footnotetext{
7 "O tecnobrega inovou instituindo a pirataria de si mesmo, como meio barato de popularizar artistas e fazer dinheiro com apresentações ao vivo. O resultado é um estrondoso sucesso local, regional e até nacional, de bandas e artistas originários do tecnobrega, que souberam conquistar milhares de consumidores vendendo a preços acessíveis a música que eles desejavam. Viraram "case" internacional e um modelo de sucesso" (Motta 2008). The tecnobrega revolution. http://blogs.oglobo.globo.com/blog-do-moreno/post/the-tecnobrega-revolution-141751.html [Fecha de consulta: 7 de septiembre de 2017].

${ }^{8} \mathrm{https}: / /$ www.traficantes.net/cultura-libre [Fecha de consulta: 7 de septiembre de 2017].
} 
publican con licencias Creative Commons que permiten la libre copia y distribución sin ánimo de lucro. Cuando los libros de la editorial salen a la venta, también se pueden conseguir en su página en versión PDF de descarga libre. La editorial Traficantes de Sueños lleva publicados más de medio centenar de libros "con distintas licencias copylelf ${ }^{9}$ y que aplica una política de acuerdos con los autores para que estos comprendan y acepten que lo mejor para sus libros es la utilización de este tipo de licencias" (Rodríguez, 2006: 74) Este modelo editorial ya no es un caso aislado, existen diferentes editoriales que han comenzado a publicar algunos libros con copyleft: Virus Editorial, Bellaterra, Acuarela, etc.

Los autores de textos pueden recibir compensación económica por su trabajo a través de cuatro vías: por medio de la publicación de su obra en papel, por medio de los derechos reprográficos ${ }^{10}$ de sus obras, por medio de contratos con instituciones públicas y privadas que financian la obra y, por último, por medio de rentas derivadas de la publicación y su popularidad. Aunque la mayor parte de autores, salvo la literatura comercial y algunos ensayos, no son remunerados por las dos vías primeras. En cambio, sí por medio de mecenazgo o subvenciones públicas o privadas y por las rentas indirectas. "De lo que se deduce que las razones esgrimidas por los derechos de autor tienen mucho más que ver con la industria editorial (que normalmente gestionan estos derechos) que con los intereses de los autores" (Rodríguez, 2006: 69).

Una sociedad sin sistema de copyright podría ser posible si el mercado no se encontrara en manos de unos pocos oligopolios. De este modo, las creaciones de un mayor número de artistas podrían llegar a un elevado público, y así el artista vivir de su trabajo, sin olvidar que exista un control y regulación de la copia y fraude, sin la necesidad de llegar a los tribunales cuando se detecta

\footnotetext{
${ }^{9}$ El copyleft es una práctica legal cuyo objeto es autorizar el libre uso y distribución de la obra, exigiendo que quienes la utilicen mantengan las mismas libertades al distribuir sus copias y derivados. Disponible en https://www.traficantes.net/culturalibre-1 [Fecha de consulta: 7 de septiembre de 2017].

${ }^{10}$ Los derechos de copia son tramitados por una sociedad de gestión colectiva, CEDRO (Centro Español de Derechos Reprográficos). Ésta se encarga de contratar licencias con los establecimientos reprográficos y de perseguir y denunciar a aquellos que no teniendo licencias copian obras de sus asociados (Rodríguez, 2006: 68).
} 
un fraude. El artista debe saber, en suma, si existe un uso injusto de los productos culturales (Smiers, 2006: 296-297).

En la actualidad, los grupos culturales tienen demasiado poder y control en la producción y distribución de las creaciones. Un grupo reducido tiene un gran control sobre un gran número de obras de arte y por eso los artistas no pueden sobrevivir económicamente ya que se encuentran en un nivel local e incomunicado dentro de un mundo del mercado global. Y de ahí que se debería intentar recuperar ese espacio independiente para las creaciones individuales, fuera de esos grupos culturales, para que hubiera una mayor diversidad cultural.

\section{Conclusiones}

En primer lugar, afirmamos que las posturas que defienden el copyright y en contra de la cultura libre se posicionan defendiendo que la cultura no puede ser gratuita. Pero se puede evolucionar, buscar o crear mercados paralelos a la propia cultura para encontrar los tan ansiados beneficios económicos. No se debería sancionar el acceso a la cultura. Como hemos dicho, las licencias Creative Commons dan libertad a la obra pero no para comercializarla.

Tenemos el ejemplo del festival de música de Brasil de Tecnobrega, movimiento que mezcla música tradicional propia y éxitos del pop rock mundial en un formato tecno, donde ninguna de las canciones son originales, son todo fusiones o transformaciones de otras canciones, ya existentes, que los músicos muestran en esos festivales. Ellos no pagan los derechos a los autores de esas canciones, las toman prestadas y no sacan beneficios directos de esa música transformada, pero sí de la publicidad que hacen durante sus conciertos o del gran número de público que accede a esos festivales. $O$, asimismo, el caso de la industria cinematográfica de Nigeria, país que se encuentra entre los primeros del mundo en producción de películas al año. Su modo de combatir la piratería es sacar al mercado, el mismo día de salida, la obra original y al mismo precio que la copia. Si original y copia se ofrecen el mismo precio, el público optará por el original. Éste es un modelo alternativo al impuesto por los mercados internacionales que beneficia la expansión de la cultura en la medida en que las películas llegan al máximo número de público a un bajo precio. En definitiva, es 
una forma de subversión contra el cine mainstream de Hollywood y de las grandes productoras internacionales occidentales.

Por otro lado, también un modelo de economía sostenible en torno a la cultura libre en el mundo editorial es haciendo viables los proyectos mediante campañas de socios, modelos de suscripción, donaciones puntuales o regulares, venta de ejemplares físicos o venta de otros productos. Se promueve un consumo cultural activista y concienciado basado en formar más una comunidad concienciada que en ayudar a crear un producto. Así en el proyecto editorial español Traficantes de Sueños.

Creemos que no sólo existe la necesidad de que las creaciones circulen para garantizar la creatividad futura y de un colectivo, sino que también existe la necesidad y el deseo de proteger a los creadores para que puedan subsistir de su creación: proteger a los creadores, buscar formas para que el autor pueda tener una recompensa de su creación. Para ello debemos encontrar un equilibro entre las dos partes de la balanza: los creadores y los nuevos creadores, con el respeto a ambas partes, a pesar de que hoy en día tendemos en exceso a proteger a los creadores y su creación, en detrimento de las creaciones derivadas y de los nuevos creadores.

En conclusión, e intentando dar respuesta a la pregunta que da título a este artículo, "Cultura Libre o Derechos de autor ¿una disyuntiva innecesaria en el siglo XXI?", en la sociedad actual de la comunicación el modelo de copyright se ha quedado obsoleto y, al no poder convivir con ello, hay que buscar nuevas alternativas. En otros lugares sobreviven mucho mejor adaptándose a la realidad, como los citados de Brasil o Nigeria. Debemos dirigir la mirada a esa visión desde la periferia, como contraposición al modelo europeoestadounidense que equivocadamente solemos considerar como universal y conseguir, con nuevos enfoques y nuevos modelos de negocio contrapuestos a los modelos generales, acabar con esa disyuntiva. 


\section{BiBLIOGRAFÍA}

BARROS, Lydia (2016). "Inclusión del tecnobrega en los nuevos procesos de circulación cultural”. En Rosana Martins, Heloisa Buarque de Hollanda y Rodrigo Saturnino (eds.) Miradas Periféricas. Las nuevas epistemologías de la comunicación en Brasil y en Portugal. Bellaterra: Institut de la Comunicació, Universitat Autónoma de Barcelona, pp. 165-186.

BUSANICHE, Beatriz (2012). “¿Por qué no hablamos de propiedad intelectual?”, Arte y cultura en circulación. Introducción al derecho de autor y las licencias libres. Argentina: Ártica Ediciones, pp.14-29.

CHIKWENDU, Madu (2007). "El fenómeno de Nollywood", Revista de la OMPI, n.ำ 3. Ginebra, pp. 8-9.

GoldsteIN, Paul [1994] (1999). El copyright en la sociedad de la información. Traducción de M.a Luisa Llobregat Hurtado. Alicante: Publicaciones Universidad de Alicante.

LESSIG, Lawrence [2004] (2005). Por una cultura libre. Cómo los grandes grupos de comunicación utilizan la tecnología y la ley para clausurar la cultura y controlar la creatividad. Traducción de Antonio Córdoba. Madrid: Traficantes de Sueños.

NANCLARES ESCUDERO, Silvia (2013). "Cultura Libre Editorial, ¿modelos sostenibles?", Teknokultura. Revista de Cultura Digital y Movimientos Sociales, vol. 10, n.. 1, pp. 253-264, en http://revistas.ucm.es/index.php/TEKN/article/view/48065/44942 [Fecha de consulta: 15 de marzo de 2016].

MARTÍNEZ SANMARTí, Roger (2012). Cultura i mercat. Barcelona: Editorial UOC.

MATA Y MARTín, Ricardo (2011). La propiedad intelectual en la Era Digital. Límites e infracciones a los derechos de autor en Internet. Madrid: La Ley.

MolTKE, Henrik et al. (2007). Película documental Good copy, bad copy, en https://www.youtube.com/watch?v=ZKiLI7XFB9k [Fecha de consulta: 1 de septiembre de 2016].

MOTTA, Nelson (2008). The tecnobrega revolution, en http://blogs.oglobo.globo.com/blog-do-moreno/post/the-tecnobregarevolution-141751.html [Fecha de consulta: 12 de septiembre de 2017].

OYEWOLE, Sandra (2014). "Una ojeada a la industria cinematográfica nigeriana", Revista de la OMPI, n. -2 , pp. 2-6, en http://www.wipo.int/wipo_magazine/es/2014/02/article_0001.html [Fecha de consulta: 12 de septiembre de 2017].

PAGOLA, Lila (2012). "Licencias libres como alternativa al copyright". En Arte y cultura en circulación. Introducción al derecho de autor y las licencias libres. Argentina: Ártica Ediciones, pp. 30-37.

Perez de Ontiveros BAquero, Carmen (1993). Derecho de autor: la facultad de decidir la divulgación. Madrid: Editorial Civitas, S.A.

RAGEL SÁNCHEZ, Luis Felipe (2005). "La propiedad intelectual como propiedad temporal”. En Carlos Rogel Vide (coord.), La duración de la propiedad intelectual y las obras en dominio público. Madrid: Editorial Reus S.A., Colección de Propiedad Intelectual, pp. 17-32.

RODRíGUEZ, Emmanuel (2006). "El copyleft en el ámbito de la edición". En Copyleft. Manual de uso. Madrid: Traficantes de Sueños, pp. 57-76. 
SÁDABA, Igor (2008). Propiedad intelectual ¿Bienes públicos o mercancías privadas? Madrid: Los libros de la Catarata.

SMIERS, Joost (2006). Un mundo sin copyright. Artes y medios en la globalización. Traducción de Julieta Barba y Silvia Jawerbaum. Barcelona: Editorial Gedisa, Serie Cultura.

Fecha de recepción: 30 de marzo de 2017

Fecha de aceptación: 15 de septiembre de 2017 